\title{
USING SUPPORT VECTOR MACHINE (SVM) FOR TIME AND COST OVERRUN ANALYSIS IN CONSTRUCTION PROJECTS IN EGYPT
}

\author{
Mohamed Gamal Eltoukhy \\ Department of Civil Engineering, Construction management, \\ German University in Cairo, Egypt \\ Ayman H. Nassar \\ Department of Civil Engineering, Construction management, \\ German University in Cairo, Egypt
}

\begin{abstract}
This study aims to model construction projects cost and time overruns, with the specific objectives of identifying the causes and effects of cost and schedule overruns in construction projects. This is because the concept of construction projects cost and schedule overruns has attracted much attention in recent years and that researchers and research bodies, be it corporate or government that try to formulate remedies to projects cost and schedule overruns should begin with an understanding of the causes of these overruns and their effects to the construction industry as a whole. Since, time and cost performance are the fundamental criteria for success of any project. The project management technique for tracking the most critical factors that affect the project's overruns of planned schedule and planned budget using tools and developed software are helpful in comparing the project with stipulated time and cost.

This research investigates ranking factors from two questionnaires to compute the severity index among various construction projects and ranked each factor according to the percentages of each factor occurrence. Two models constructed using Linear regression (LR) and machine learning (Support Vector Machine) is one of the artificial intelligence systems to fit the given data for all construction projects. First model is developed for time overrun prediction with high accuracy and second model is developed for cost overrun for various construction projects. Check the performance and accuracy of the predicting model by some certain projects of time and cost projects data and check the variation of the results between the actual results and predicted results.
\end{abstract}

Keywords: Schedule overruns, Cost overruns, Construction Industry, Project management, Causes and effect of cost and schedule overruns, Contractor, Owner, Consultant, Machine learning, Artificial intelligence, Support Vector Machine (SVM) 
Cite this Article: Mohamed Gamal Eltoukhy and Ayman H. Nassar, Using Support Vector Machine (SVM) for Time and Cost Overrun analysis in Construction Projects in Egypt, International Journal of Civil Engineering and Technology (IJCIET), 12(3), 2021, pp. 5-22.

https://iaeme.com/Home/issue/IJCIET?Volume $=12 \&$ Issue $=3$

\section{INTRODUCTION}

Construction delay means a time and cost overrun either beyond the contract date, the contract value beyond the date that the parties have agreed upon for the delivery of the project. In both cases, a delay is usually a costly situation. Schedule and cost overruns can occur for a wide variety of reasons on various types of projects which has led to the debate on how to minimize these construction projects cost and schedule overruns. The main objectives of projects control are to ensure that projects finish on time, within budget and achieve other project objectives.

Time overrun can be defined as late completion of works as compared to the planned schedule or contract schedule. It occurs when the progress of a contract falls behind its scheduled program. It may be caused by any party to the contract and may be a direct result of one or more circumstances. Construction cost is one of the peak criteria of success of a project throughout its lifecycle and is of high concern to those who are involved in the construction industry. Cost overrun can be considered as the difference between actual cost of a project and its Cost limit.

There are two questionnaires of project's time and cost overrun. The first one was investigated by 50 contractors, 13 consultants and 9 owners.

In this researcher 40 factors of delays were identified and these factors were grouped into 7 categories. It was concluded in survey that all factors related to the labors, contractor, project, owner and consultant are on the highest rank and all three parties agreed to change order. The second one contained of 42 factors of cost overrun impact factors and divided to 7 groups. It was investigated by 45 contractors, 15 consultants and 11 owners and it was concluded that all factors related to the financial issues faced and scope changes by the owner, project's experience related to the contractor, consultant, and contract type.

\section{PROBLEM STATEMENT}

Construction projects in many countries are still facing problem of time and cost overrun which needs very serious attention. Egyptian construction industry is also facing the same problem of time and cost overrun. To avoid this issue, the most important step is to identify and understand the causes and factors responsible for that. Hence, this study was carried out to identify the major cause of time and cost overrun in Egyptian construction industry.

\section{OBJECTIVE AND SCOPE}

The main objective of this study is to specify, analyze the impact factors for time and cost overruns for construction projects to be capable of model the factors that affect time and cost overrun in construction projects in Egypt. For model development and implementation using Support Vector Machine (SVM) is one of the Artificial Intelligence (AI) Tools and techniques to predict the project's time and cost overruns depend on the database were collected from the respondents. 


\section{RESEARCH MODEL DEVELOPMENT}

- Identify the factors which effect on time and cost overrun of construction projects in Egypt.

- Determine the most critical factors that affect cost overrun.

- Give the future recommendations to reduce those critical factors in upcoming projects.

- Compare the accuracy and variance models of predicting between two models: Linear Regression algorithm and as well as support vector machine to predict the final time and cost for construction projects.

- Develop software according to the more accurate model to permit the users to predict the time and cost for the future projects.

- This study presented two models designed and developed for this study that allows the user to predict the project time and cost overrun reliably in Egypt. Two models are an essential part of the study which has been commonly used to solve the complex pattern identification problem with a large number of features with a clear connection to the underlying statistical learning theory and widely usage for predictive models. Models designed based on the factors that affecting time and cost overrun and have been developed using machine learning (Support Vector Machine). The support Vector Machine (SVM) is one of the Artificial Intelligence (AI) Tools and techniques. A time overrun model having 40 support vectors in the input layer, only one hidden layer was developed having 40 support vectors and finally a vector in the output layer. A cost overrun model having 42 support vectors in the input layer, only one hidden layer was developed having 42 support vectors and finally a vector in the output layer. The time overrun designed model for this study was tested by one out of the collected data projects to check the variance between the actual overrun and the predicted overrun was found to be $24 \%$ which is acceptable and the cost overrun designed model for this study was tested by one out of the collected data projects to check the variance between the actual overrun and the predicted overrun was found to be $20 \%$ which is acceptable also.

\section{LITERATURE REVIEW}

\subsection{Time Overrun Studies in Construction Projects}

Time overrun is defined as the extension of time beyond planned completion date specified in contract or beyond the date that parties agreed upon for delivery of project (T. Subramani et al Int. 2014). Also defined as "the extension of time beyond planned completion dates traceable to the contractors" (T. Subramani et al Int. 2014). Delays are incidents that impact a project's progress and postpone project activities.

$$
\text { Time overrun ratio }=\left(\frac{\text { actual schedule }- \text { Planned schedule }}{\text { Planned schedule }}\right)
$$

Delay causing incidents may include weather delays, unavailability of resources, design delays, etc. In general, project delays occur as a result of project activities that have both external and internal cause and effect relationship (Vidalis et al 2002). Choudhry (2004) and Chan (2001), "Defined the time overruns as the difference between the actual completion time and the estimated completion time". (Elinwa and Joshua 2001).

Similarly (Mansfield et al. 1994) showed that the most significant factors affecting construction schedules were financing and payment for completed works, poor contract management, changes in site conditions, shortage of materials, and improper planning.

According to (Assaf and Al-Hejji 2006) 70\% of projects experienced time overrun. The average time delay ranges from $10 \%$ to $30 \%$ of the original duration of the project. The study 
identified 6 main causes including change order, delay in progress payment, ineffective planning and scheduling of project by contractor, poor site management and supervision by contractor, Shortage of labors and Difficulties in financing project by contractor as most critical factors responsible for this time overrun. Delayed payment was found to be the number one cause of schedule delays in the Zambian road construction industry followed by protracted financial processes in client organizations, financial difficulties that accompany the delayed release of funds by client organizations, contract modification, material procurement and changes in drawings, staffing problems, equipment unavailability, poor supervision, construction mistakes, poor coordination on site and changes in specifications (kaliba et. Al. 2009). Unforeseen site conditions were found most prominent cause of schedule delay affecting total project duration and cost of project (Yang and Ou 2008).

Similarly (Mansfield et al. 1994) showed that the most significant factors affecting construction schedules were financing and payment for completed works, poor contract management, changes in site conditions, shortage of materials, and improper planning.

While Alaghbari et al. (2007) studied the problem of time overrun and found that the top ten significant factors of time overrun include financial difficulties by owner, financial problems by contractor, supervision too late, slowness in making decisions and slow give instructions by consultant, lack of material by external factor, poor site management, materials shortage, construction mistakes and delay delivery of materials by contractor, slowness making decision by owner, lack of experience and incomplete documents by consultant. In another study, Sambasivan and Soon (2007) found that most important causes of time overrun were contractor's improper planning, mistakes during construction stage, inadequate contractor experience, inadequate client's finance and payments for completed work and lack of communication.

It has been reported by several researchers that delays are common in the construction sector worldwide. The average time overrun in construction projects in Saudi Arabia was between $10 \%$ and $30 \%$ and only $30 \%$ of the projects finished within the planned date of completion (Assaf and Al-Hejji, 2006). Ajanlekoko (1987) (as cited by Sambasivan and Soon, 2007) stated that performance of construction projects in Nigeria was poor in terms of time.

In Ghana, (Frimpong et.al. 2003) studied ground water project and illustrated that owners, contractors and consultants ranked poor contractor management, monthly payment difficulties from agencies, material procurement, poor technical performances and escalation of material prices as major factors that can cause time overrun.

While Alaghbari et al. (2007) studied the problem of time overrun and found that the top ten significant factors of time overrun include financial difficulties by owner, financial problems by contractor, supervision too late, slowness in making decisions and slow give instructions by consultant, lack of material by external factor, poor site management, materials shortage, construction mistakes and delay delivery of materials by contractor, slowness making decision by owner, lack of experience and incomplete documents by consultant. In another study, Sambasivan and Soon (2007) found that most important causes of time overrun were contractor's improper planning, mistakes during construction stage, inadequate contractor experience, inadequate client's finance and payments for completed work and lack of communication.

\subsection{Cost Overrun Studies in Construction Projects}

According to (Zhu et al 2004) "cost overrun is defined as excess of actual cost over budget". Cost overrun is also sometimes called "cost escalation," "cost increase," or "budget overrun." (Al-Najjar 2008). (Choudhry 2004) "Defined cost overrun as the difference between the 
original cost estimate of project and actual construction cost on completion of works of a commercial sector constriction project" (Ubani et al. 2015).

Cost overrun is defined as an instance in which the provision of contracted goods or services are claimed to require more financial resources than was originally agreed between a project sponsor and a contractor (NEGA 2008). (Wideman 2002) defined cost overrun as the amount by which actual costs exceed the baseline or approved costs.

$$
\text { cost overrun ratio }=\left(\frac{\text { actual budget }- \text { estimated budget }}{\text { etimated budget }}\right)
$$

Okpala and Aniekwu searched for the main causes of cost overruns in Nigeria, and found out that the main causes were shortage of materials, problems regarding finance and payment for completed works, poor contract management, price fluctuations and fraudulent practices (Okpala and Aniekwu,1988).

Cost overruns do not just occur naturally, there are a number of factors during the construction process that when not managed properly can lead to cost overruns. Al-Najjar (2008) identified a total of 42 factors that cause cost overruns and ranked the top ten causes as follows: Technical incompetence, poor organizational structure, and failures of the enterprise, lack of cost reports during construction stage, inadequate project preparation, planning and implementation, delays in issuing information to the contractor during construction stage, lack of coordination at design phase, change in the scope of the project or in Government policies, Some tendering maneuvers by contractors, such as front- loading of rates, incomplete design at the time of tender, bad allocation of labor inside the site and delays in decisions making by government were ranked the top ten causes of cost overruns. Olawale and Sun (2010) states that despite the availability of various control techniques and project control software many construction projects still do not achieve their cost objectives. Hence, despite its proven importance it is not uncommon to see a construction project failing to achieve its objectives within the specified cost.

Enshassi et al. (2009) analyzed the major factors causing cost overruns which includes fluctuations in the cost of building materials, increment of materials prices due to continuous border closures, delay in construction, supply of raw materials and equipment by contractors, unsettlement of the local currency in relation to dollar value, project materials monopoly by some suppliers, resources constraint, lack of cost planning/monitoring during pre-and postcontract stages, funds and associated auxiliaries not ready, design changes, improvements to standard drawing during construction stages and inaccurate quality take-off. Omoregie and Radford (2006) studied the factors influencing cost overrun of infrastructure projects in Nigeria. The major factors of cost overruns imported materials and plant items, additional works, shortage of materials, inaccurate estimate, nominated suppliers and subcontractors, nonadherence to contract conditions, mistakes and discrepancies in contract condition, mistakes and discrepancies in contract conditions, design changes, weather, mistakes and discrepancies in contract condition and are price fluctuation, financing and payments of complete works, poor contract management, schedule delay, changes in site condition and fraudulent practices. Kikwasi, G.J. (2012) identified fourteen effects of delays in Tanzania and ranked them as follows; time overrun, cost overrun, negative social impact, idling resources, disputes, arbitration, delaying by the client to return the loans, poor quality of work due to hurrying the projects, delaying in getting profit by clients, bankruptcy, litigation, create stress on contractors, total abandonment and acceleration losses.

Le-Hoai et al., (2008) studied the causes of time and cost overrun in large construction project of Vietnam using questionnaire survey. The investigation included 21 causative factors and top 5 common and very sever causes of cost overrun were poor site management and 
supervision, poor project management assistance, financial difficulties of owner, financial difficulties of contractor; design changes.

This is very essential as time and cost performance cannot be improved without controlling the causative risk factors. In this regard, various researches have highlighted numerous factors. Jackson (2002) studied reasons of budget overrun in UK through questionnaire survey and found that major reasons of overrun were design changes, design development factors, information availability, method of estimation, performance of design team and project management.

\section{THEORETICAL FRAMEWORK}

This section objected for giving a brief description about time management strategy and cost management strategy, how to implement it according to the PMI, in addition to giving an introductory overview about history of Artificial intelligence (AI), implementation of machine learning techniques, Support Vector Machine (SVM) technique and its machine learning classification and linear regression (LR), Support Vector Machine types, margins (limitations) and technical notes about (SVM).

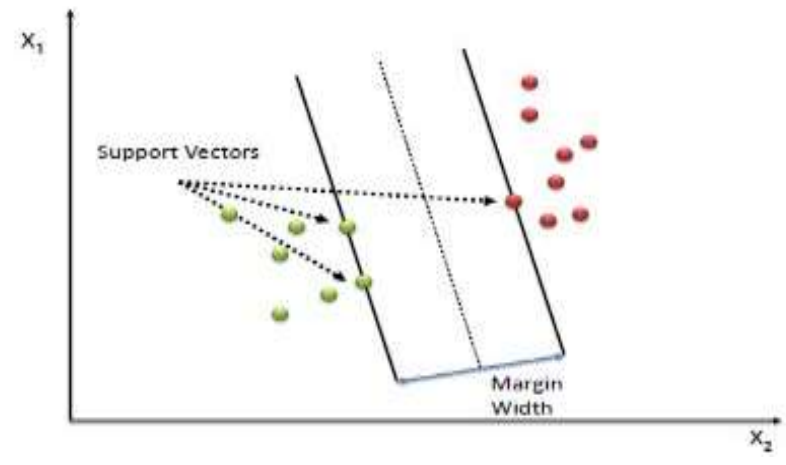

Figure 2

\subsection{Artificial Intelligence}

It is the ability of a computer program or a machine to think and learn. It is also a field of study which tries to make computers "smart". They work on their own without being encoded with commands. John McCarthy came up with the name "artificial intelligence" in 1955.

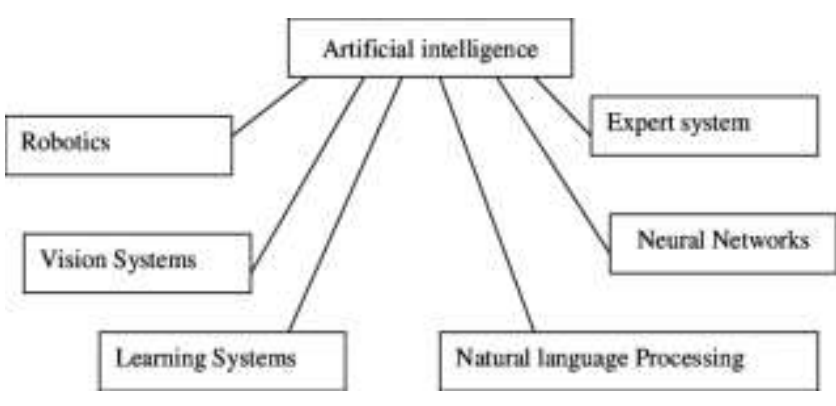

Figure 2

\subsection{Support Vector Machine (SVM)}

A Support Vector Machine (SVM) is a discriminative classifier formally defined by a separating hyperplane. In other words, given labeled training data (supervised learning), the algorithm outputs an optimal hyperplane which can be used for both classification or regression challenges. Support vector machine used to maximize the margin "aka street width" around 
hyperplane, the decision function is determined based on the subset of training sample called support vectors, that's become a quadratic problem (2-Dim) can be solved by standard methods. The support vector machine contains inputs $\mathrm{x}_{1}, \mathrm{x}_{2}, \ldots \ldots \mathrm{x}_{\mathrm{i}}$ and the desired output $\mathrm{y}$ and set of weights used to the optimization of the maximizing margin. Although, the decision boundaries are moving while the support vector moves only. In most cases, it will be difficult to separate between classes by line, as a result, the SVM uses a set of mathematical functions called Kernels. Kernels are processes of mapping objects or rearranging objects to transform the complex curve into the linear separation between samples.

\subsection{Linear Regression (LR)}

Linear Regression is a machine learning algorithm based on supervised learning. It performs a regression task. Regression models a target prediction value based on independent variables. It is mostly used for finding out the relationship between variables and forecasting. Different regression models differ based on the kind of relationship between dependent and independent variables, they are considering and the number of independent variables being used. (Y) dependent variable, $(\mathrm{X})$ independent variable So, this regression technique finds out a linear relationship between $\mathrm{x}$ (input) and $\mathrm{y}($ output). $\mathrm{Y}=\mathrm{m}(\mathrm{x})+\mathrm{b}$.

\section{METHODOLOGY}

Regarding to achieve the objectives of the study, the research proceeds these stages:

- Identify the factors that effect on time and cost overrun from the literature review and classified them to seven desired categories.

- Identifying the most relevant and important factors that affect time and cost overrun occurred in construction projects. Regarding to previous research were reviewed for identification of various factors causing time and cost overrun for construction projects. Based on past research 40 factors were identified to have an impact on time overrun for construction projects and 42 factors were identified to have an impact on cost overrun for construction projects.

- A questionnaire surveys were conducted for construction projects (contractors, consultants, client) to rank the factors that impact of time and cost overrun.

- The data were successfully collected for the two questionnaires from experienced participants and different ages from several organizations. The first questionnaire for time overrun had 72 respondents about time overrun in construction projects; the second questionnaire for cost overrun had 70 respondents about cost overrun in construction projects

- Impact scale index uses to rank the factors according to the respondents obtained from the questionnaire survey to determine the most critical factor

- Comparing the two artificial intelligence (AI) models (SVM, LR) to find the most accurate model that predicts the time and cost overrun percentages.

- Testing the time and cost predicting models by new projects that not included for the dataset.

- Identifying the mean squared error and variance score for the models using (SVM, LR)

$$
\operatorname{accuracy\_ score}(y, \hat{y})=\frac{1}{n_{\text {sample }}} \sum_{i=0}^{n_{\text {sample }}-1} 1\left(y_{i}=\hat{y}_{i}\right)
$$


where it used two methods to evaluate the model's accuracy; variance score for classification and mean squared error for regression. The accuracy score function calculates the accuracy, either the fraction

(default) or the count (normalize=False) of correct predictions. If $y_{i}$ is the actual value or the true value of the $i$-th sample, while $\hat{y}_{i}$ is the predicted value of the $i$-th sample so the friction of correct prediction over $n_{\text {sample }}$ is calculated as:

$$
\operatorname{MSE}(y, \hat{y})=\frac{1}{n_{\text {sample }}} \sum_{i=0}^{n_{\text {sample }}-1}\left(y_{i}-\hat{y}_{i}\right)^{2}
$$

Thus, in this study two different algorithms were attempted to calculate the time and cost (SVM and LR).

First phase: Identify the factors that effect on time and cost overrun from the literature review and classified them to seven desired categories.

Second phase: The study involved the identification of factors that effect on time overrun that faced construction projects which derived from several previous studies that were examined from different countries all over the world and then the factors were filtered to exclude the repeated factors, totally 40 factors were defined and divided into seven categories according to the source of time overruns; factors related to contractor related causes, client related causes, consultant related causes, resources related causes (Construction material related cause, Labor related cause, Project related cause) and External related factors

Third phase: The identification of factors that effect on cost overrun that faced construction projects which derived from several previous studies that were examined from different countries all over the world and then the factors were filtered to exclude the repeated factors, totally 42 factors were defined and divided into seven categories according to the source of cost overruns; (factors related to contractor related causes, client related causes, consultant related causes, resources related causes) (Construction material related cause, Labor related cause, Project related cause) and External related factors.

\section{FACTORS AFFECTING TIME OVERRUN IN CONSTRUCTION PROJECTS}

\subsection{Client Related Causes}

- High quality of finishes needed

- A suspension of work by owner

- Design changes

- Time needed for Decisions to be taken

- Financial constraints faced the owner

- Difficulties in obtaining work permits

- Delays in contractors claims settlements

- Change orders from owner

\subsection{Contractor Related Causes}

- Information flow between project team members

- A suspension of work by contractor

- sufficient number of staffs 
- Site management.

- The contractor Spend some time to find sub-contractors' company who is appropriate for each task.

- Lack of protection of complete work

- Mistakes during construction

- Contractor experience for the project

- Equipment allocation problems

- Follow up for the project schedule and continuous tracking

- Judgment in estimating time and resources

- Delay in mobilization

- Shortage of equipment, manpower

\subsection{Consultant Related Causes}

- flexibility of donor in giving appropriate periods for project implementation.

- Experience on the part of the consultant's site- staff; (managerial and supervisory, Personnel)

- Delay of materials approval

- Centralization of decision-making process.

- The response by the consultant's engineers regarding testing and inspections

\subsection{Construction Material Related Cause}

- Modification in material specifications

- Delay in material delivery

\section{5 labor Related Causes}

- Productivity of labors.

- Labor Skills.

\subsection{Project Related Cause}

- the planned schedule of the project suitable.

- consistency between the project and its environmental due to donor agenda.

- Information about project at Tender Stage.

- Communication and coordination between parties.

- Discrepancies between contract documents.

- Provision of information to project participants.

- Quantity variations.

\subsection{External Related Causes}

- Location of project and distance to vendors.

- Unknown geological conditions.

- Weather conditions on the job site. 


\section{Classification of participants for Time overrun questionnaire (\%)}

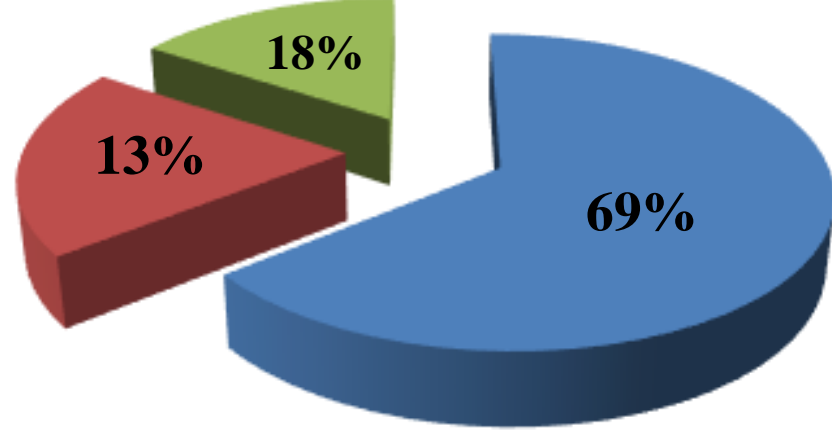

Figure 4

\section{FACTORS AFFECTING COST OVERRUN IN CONSTRUCTION PROJECTS}

\subsection{Client Related Causes}

- Quality requirements

- Scope changes

- Design changes

- the project faced problems according to the financial condition of the owner

- Time needed for Decisions to be taken

\subsection{Contractor Related Causes}

- project faced problems according to cash flow of the contractor

- the risk of quantity variations

- The contractor has required knowledge and is completely aware of the project

- the prequalification of the contractor suitable for the project

- Site management

- the equipment used in the project suitable / adequate Mistakes during construction.

- the contractor performs similar projects before and has the required experience.

- The accessibility of the site.

- the project experience inefficient planning and scheduling.

- the project experience shortage of equipment during implementation.

- Contractor have cost control.

- The category/Class of the contractor.

\subsection{Consultant Related Causes}

- Design Approvals

- Delay in consultant approvals Delay of materials approval. 


\subsection{Construction Material Related Cause}

- estimation of the material

- delay in the delivery of material

- Increase of material cost

\subsection{Labor Related Causes}

- shortage in labors

- Labor skills

- The productivity of labor and equipment

\subsection{Project Related Cause}

- Competition at Tender stage to guarantee the project

- Fluctuation of the currency for payment

- Design of the project complexity

- The planned schedule of the project suitable

- The project size (Scale)

- Information about project at Tender Stage

- Distance to vendors

- The project experience conflicts between involved parties

- The advanced payment low/incompatible to the project

- The project the workload

- The project has adequate Dispute settlement procedure

- The project has tough inspection and testing procedures

- Sufficient/Adequate safety procedures and procedures followed

- Procurement method

- The permits by Governmental agencies

\subsection{External Related Causes}

- Unknown geological conditions

- Location of project and distance to vendors

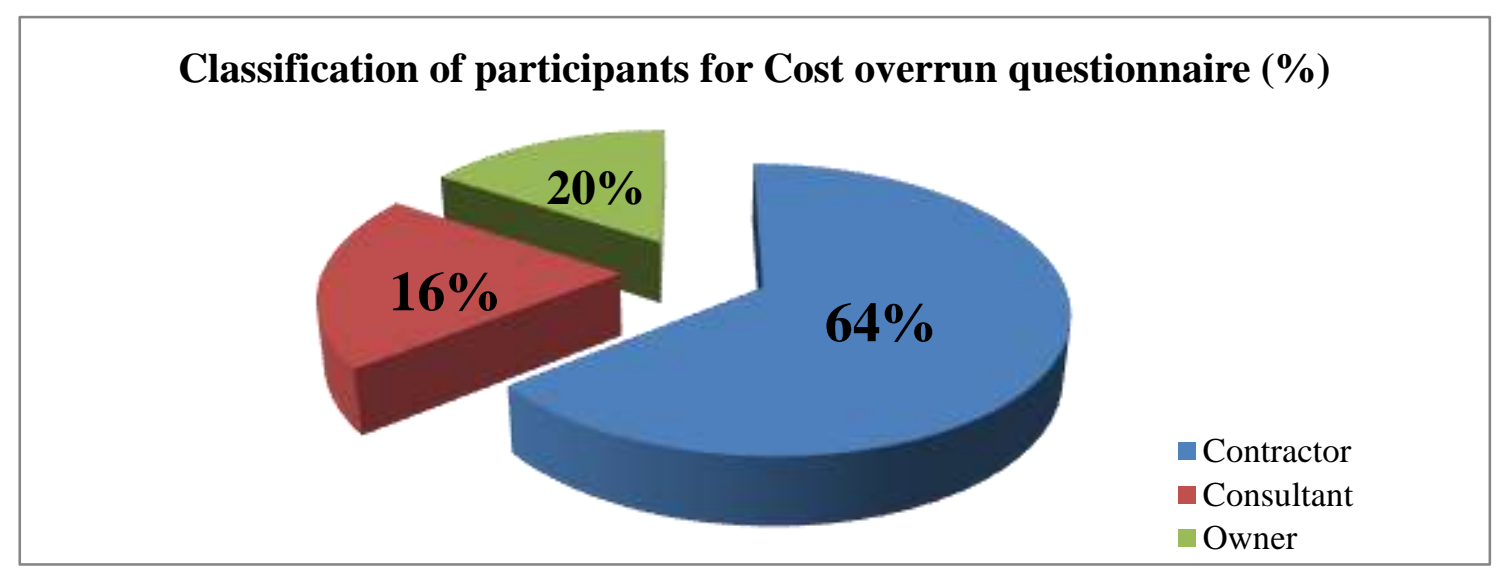

Figure 3 
Fourth phase: the questionnaire survey was conducted in the third phase among the participants of projects that faced time and cost overrun in construction projects (consultants, contractors, sub-contractors, clients) to select the impact severity of each factor based on their experiences on the factors that studied in the previous stage, the impact severity of each factor scaled from 1 to 5 (1=highest, $5=$ lowest) and percentages of time and cost overrun for each project. The participants answered this questionnaire depending on their previous experience in construction projects and two charts below indicate the classification of participants percentage for questionnaires.

Fifth phase: ranking for factors using impact scale index uses according to the respondents obtained from the questionnaire survey to determine the most critical factors.

In this phase real cases of previous projects were collected 142 surveys from different involved companies (client, contractor, consultant) each project explained the severity of each factor on the project and the time and cost of the completion overrun percentages. 72 project faced time overrun and 70 project faced cost overrun.

For time overrun questionnaire: Impact scale (Severity index) $(\mathrm{SI})=($ Number of respondents $* 1+$ Number of respondents $* 2+$ Number of respondents*3+ Number of respondents*4+ Number of respondents*5)/ (72).

For cost overrun questionnaire: Impact scale (Severity index) $(\mathrm{SI})=($ Number of respondents* $1+$ Number of respondents*2+ Number of respondents*3+ Number of respondents $* 4+$ Number of respondents $* 5) /(70)$.

Sixth phase: In the sixth stage, two models were used (support vector machine, linear regression), whereas the fourth stage outputs were the inputs of the models. On the other hand, cross-validation method was used to mitigate overfitting of the model where the dataset was divided into $90 \%$ training dataset and $10 \%$ testing dataset and Comparing the mean squared error and variance score for the two artificial intelligence (AI) models (SVM, LR) to find the most accurate model that predicts the time and cost overrun percentages.

\section{RESULTS AND ANALYSIS}

\subsection{Data Collected}

The time overrun questionnaires were distributed among 165 participants from different ages and experiences (contractors, consultants, clients). It was accomplished among several contractors and consultants and owners who related to construction field. However, 142 out of 165 questionnaires were answered and collected successfully.

For time overrun questionnaire, the results showed that 72 out of 85 participants were collected successfully 50 were contractors, 9 were clients, 13 consultants. For cost overrun questionnaire, the results showed that 70 out of 80 respondents were collected successfully 45 were contractors, 11 were clients, 14 consultants.

Furthermore, respondents for time overrun questionnaire 32 of them have 5-10 years of experience and 16 of them have 10-15 years of experience the 24 have more than 15 years' experience in construction field. respondents for cost overrun questionnaire 29 of them have 510 years of experience and the 41 have more than ten years' experience in construction field.

Furthermore, 11 of the respondents have 1-2 years of experience in road construction projects, 19 of them have 3-5 years, 19 of them have 5-10 years of experience and the rest have more than ten years' experience in road construction projects. 


\subsection{Analysis of the Responses}

For First questionnaire: The data were collected successfully and calculated the average value of the impact of each factor as well as the project time overrun percentage. Finally, the results showed the critical factor that effected on time overrun resulted from the questionnaire. Top five factors that affect time overrun (geological conditions, Suitability of the project planned schedule, Design changes, change orders from owner, Shortage of equipment, manpower \& material)

Table 1 Ranking the factors which effect on time overrun of construction projects in Egypt

\begin{tabular}{|c|c|c|c|}
\hline $\begin{array}{c}\text { Factor } \\
\text { ID }\end{array}$ & Factor & $\begin{array}{l}\text { Average } \\
\text { severity }\end{array}$ & Rank \\
\hline F1 & Suitability of the planned schedule of the project & 3.58 & 2 \\
\hline F2 & Inflexibility of donor in giving appropriate periods for project implementation & 2.21 & 31 \\
\hline F3 & High quality of finishes needed & 2.83 & 17 \\
\hline F4 & Discrepancies between contract documents & 2.00 & 35 \\
\hline F5 & Slow information flow between project team members & 2.13 & 32 \\
\hline F6 & Suspension of work by owner or contractor? & 2.36 & 27 \\
\hline F7 & consistency between the project and its environmental due to donor agenda? & 2.57 & 24 \\
\hline F8 & Location of project and distance to vendors? & 2.83 & 18 \\
\hline F9 & The drawings are detailed or not (Design changes) & 3.54 & 3 \\
\hline F10 & Sufficient number of staffs (contractor) & 2.36 & 29 \\
\hline F11 & Productivity of labors & 3.11 & 9 \\
\hline F12 & Labor Skills & 2.67 & 21 \\
\hline F13 & Site management & 2.53 & 25 \\
\hline F14 & Lack of experience on the part of the consultant's site- staff; (managerial and supervisory, Personnel) & 1.49 & 40 \\
\hline F15 & contractor Spend some time to find sub- contractors' company who is appropriate for each task & 1.67 & 38 \\
\hline F16 & the project has unknown geological conditions & 3.61 & 1 \\
\hline F17 & Equipment allocation problems & 2.79 & 19 \\
\hline F18 & Lack of protection of complete work & 2.63 & 22 \\
\hline F19 & project scale & 2.75 & 20 \\
\hline F20 & Information about project at Tender Stage & 2.97 & 13 \\
\hline F21 & Time needed for Decisions to be taken & 2.36 & 28 \\
\hline F22 & Delay in material delivery & 2.89 & 15 \\
\hline F23 & Communication and coordination between parties & 2.39 & 26 \\
\hline F24 & Mistakes during construction & 2.11 & 33 \\
\hline F25 & Contractor experience for the project & 2.61 & 23 \\
\hline F26 & Delay of materials approval & 3.10 & 10 \\
\hline F27 & Centralization of decision-making process from consultant party & 1.64 & 39 \\
\hline F28 & Provision of information to project participants & 2.00 & 36 \\
\hline F29 & financial constraints faced by the owner & 3.15 & 7 \\
\hline F30 & Quantity variations & 2.83 & 16 \\
\hline F31 & Follow up for the project schedule and continuous tracking & 3.13 & 8 \\
\hline F32 & Judgment in estimating time and resources & 3.22 & 6 \\
\hline F33 & Modification in material specifications & 2.07 & 34 \\
\hline F34 & Shortage of equipment, manpower \& material & 3.33 & 5 \\
\hline F35 & Difficulties in obtaining work permits & 3.01 & 11 \\
\hline F36 & Delay in mobilization & 1.78 & 37 \\
\hline F37 & Delays in contractors claims settlements & 3.00 & 12 \\
\hline F38 & Severe weather conditions on the job site & 2.32 & 30 \\
\hline F39 & Change orders from owner & 3.46 & 4 \\
\hline F40 & The response by the consultant's engineers regarding testing and inspections & 2.92 & 14 \\
\hline
\end{tabular}

For cost overrun questionnaire, the results showed that 70 out of 80 participants were collected successfully 45 were contractors, 11 were clients, 14 consultants. 
Moreover, respondents for cost overrun questionnaire 29 of them have 5-10 years of experience and 16 of them have 10-15 years of experience and 25 have more than 15 years' experience in construction field. respondents for cost overrun questionnaire 29 of them have 510 years of experience and the 41 have more than ten years' experience in construction field.

\subsection{Analysis of the Responses}

For Second questionnaire: The data were collected successfully and calculated the average value of the impact of each factor as well as the project cost overrun percentage. Finally, the results showed the critical factor that effected on cost overrun resulted from the questionnaire. Top five factors that affect cost overrun (Fluctuation of the currency for payment, the project faced problems according to the financial condition of the owner, Unknown geological conditions, the required experience for contractor that perform similar projects before. Scope changes by the owner).

Table 2 Ranking the factors which effect on cost overrun

\begin{tabular}{|c|c|c|c|}
\hline $\begin{array}{l}\text { Factor } \\
\text { ID }\end{array}$ & Factor & $\begin{array}{l}\text { Average } \\
\text { severity }\end{array}$ & Rank \\
\hline F1 & The estimation of the material was accurate & 3.59 & 7 \\
\hline $\mathrm{F} 2$ & Design changes & 3.24 & 13 \\
\hline F3 & Did the project faced problems according to the financial condition of the owner? & 4.01 & 2 \\
\hline $\mathrm{F} 4$ & Did the project faced problems according to cash flow of the contractor? & 2.99 & 20 \\
\hline F5 & Is there a competition at Tender stage to guarantee the project? & 3.06 & 16 \\
\hline F6 & Fluctuation of the currency & 4.09 & 1 \\
\hline F7 & Were the quality requirements satisfied? & 2.93 & 21 \\
\hline F8 & Delay in consultant approvals & 3.01 & 17 \\
\hline F9 & Was the Design of the project complex? & 2.77 & 25 \\
\hline F10 & Did the project experience scope changes by the owner? & 3.66 & 5 \\
\hline F11 & Was the planned schedule of the project suitable or not? & 2.09 & 42 \\
\hline F12 & Did the project has unknown geological conditions? & 3.84 & 3 \\
\hline F13 & Did the project experience delay in Design Approvals? & 3.07 & 15 \\
\hline F14 & Project size & 2.43 & 35 \\
\hline F15 & Information about project at Tender Stage? & 2.37 & 37 \\
\hline F16 & Time needed for Decisions to be taken? & 3.26 & 12 \\
\hline F17 & Location of project and distance to vendors? & 2.46 & 34 \\
\hline F18 & Did your side take the risk of quantity variations? & 3.59 & 8 \\
\hline F19 & Did the contractor has required knowledge and is completely aware of the project? & 2.86 & 23 \\
\hline F20 & Did the project experience conflicts between involved parties? & 2.34 & 40 \\
\hline F21 & Was the advanced payment low/incompatible to the project? & 3.53 & 9 \\
\hline F22 & Was the prequalification of the contractor suitable for the project? & 2.46 & 32 \\
\hline F23 & The workload in the project & 2.34 & 39 \\
\hline F24 & Did the contract type put many risks on the contractor? & 3.51 & 10 \\
\hline F25 & Did the project has adequate Dispute settlement procedure? & 2.37 & 38 \\
\hline F26 & Did the project has tough inspection and testing procedures? & 2.41 & 36 \\
\hline F27 & Site Management & 2.89 & 22 \\
\hline F28 & Were sufficient/Adequate safety procedures and procedures followed? & 2.66 & 28 \\
\hline F29 & Were the equipment used in the project suitable / adequate? & 2.46 & 33 \\
\hline F30 & Did the contractor perform similar projects before and has the required experience? & 3.69 & 4 \\
\hline $\mathrm{F} 31$ & The accessibility of the site & 2.66 & 29 \\
\hline F32 & Procurement method & 3.60 & 6 \\
\hline F33 & Did the project experience inefficient planning and scheduling? & 2.84 & 24 \\
\hline F34 & Did the project experience shortage of equipment during implementation? & 3.00 & 19 \\
\hline
\end{tabular}




\begin{tabular}{|l|l|c|c|}
\hline F35 & Did the project suffer from delay in the delivery of material? & 2.71 & 27 \\
\hline F36 & Did the project experience shortage in labors? & 3.16 & 14 \\
\hline F37 & Increase of material cost & 3.29 & 11 \\
\hline F38 & Labor skills & 2.74 & 26 \\
\hline F39 & The productivity of labor and equipment & 2.33 & 41 \\
\hline F40 & Contractor has cost control & 3.01 & 18 \\
\hline F41 & The category/Class of the contractor & 2.57 & 30 \\
\hline F42 & The permits by Governmental agencies & 2.54 & 31 \\
\hline
\end{tabular}

\subsection{Testing the Time and Cost Overrun Models}

Testing for the time overrun software by using (SVM \& LR) for a case study project which is out of collected data base projects and check the mean squared error (MSE and variance score (R2) results and compare between the predicted result of the research model and the actual result. The project was unit rate contract, there was a shortage of manpower and equipment, the contractor had lack of knowledge and experience to the similar project so there was many repeating a lot of works and the contractor spend too much time for nominating a specialized subcontractor. The project had an actual time overrun $25 \%$. After training models, the results show that the variance score (R2) of the time overrun predicting model using "SVM, LR" as the Following: The variance of results (predicted-actual) $=19-25=6 \%$, Error Percentage \%= $(19-25) / 25 * 100=24 \%$, The error percentage is $24 \%$ indicates that the variance is applicable.

Testing for the cost overrun software by using (SVM \& LR) for a case study project which is out of collected data base projects and check the mean squared error (MSE) and variance score (R2) results and compare between the predicted result of the research model and the actual result. The project was fast-tracking project and the period took to the completion date 26 months for completing all project phases. The project contract was lump sum contract and the project's size was big and divided to two parcels. The project had a major loss for cost overrun during the construction according to miss-coordination between site and the technical office at the stairs levels for the seven typical model and executed and all the works repeated at finishing items, the contractor faced a problem at cash flow during the project, the contractor project managers has a lack of experience that lead to decision-making slowly, the site management was so poor. the project had an actual cost overrun 5\%. The results show that the variance score (R2) of the cost overrun predicting model using "SVM, LR" as the following . The variance of results $($ predicted-actual $)=6-5=1 \%$, Error Percentage $\%=(6-5) / 6 * 100=20 \%$. The error percentage is $20 \%$ indicates that the variance is applicable.

\section{CONCLUSION}

Construction projects in many countries are still facing problem of time and cost overrun which needs very serious attention. Egyptian construction industry is also facing the same problem of time and cost overrun. To avoid this issue, the most important step is to identify and understand the causes and factors responsible for that. Hence, this study was carried out to identify the major cause of time and cost overrun in Egyptian construction industry. The study analyzed the most critical causes according to past studies of construction industry that occur delays and cost overruns in construction projects in Egypt. The feedback of construction parties was obtained through interviews and questionnaire surveys. the ranking of the impact factors according to severity index for each factor for project's time and cost overrun are calculated due to the response of the participants for each project and the factors for both are ranked from highest to lowest. The most important delay and cost overrun causes are classified to seven groups and the factors are prioritized according to their significance levels to five levels (Very High, High, Medium, Low and Very low) for statistical data analysis. Severity index (SI) was used to rank the factors based on questionnaires survey among (contractors, clients, consultants). finally, it 
was concluded from this study that the top five factors affected on time overrun in construction projects are: (1) geological conditions, (2) Suitability of the project planned schedule, (3) Design changes, (4) change orders from owner, (5) Shortage of equipment, manpower \& material and top five factors effect on cost overrun in construction projects: (1) Fluctuation of the currency for payment, (2) the project faced problems according to the financial condition of the owner, (3) Unknown geological conditions, (4) the required experience for contractor that perform similar projects before, (5) Scope changes by the owner. Moreover, 72 projects that faced time overrun and 70 projects that faced cost overrun used as an input for database for time and cost overrun predicting models using (Support Vector Machine (SVM) and Linear Regression (LR)). The results determined the most accurate model for time and cost overrun predicting was Support Vector Machine (SVM) with root mean squared error (MSE) for time overrun forecasting model was (6.001) and for cost overrun forecasting model was (8.30), on the other hand linear regression model (LR) with root mean squared error (MSE) for time overrun forecasting model was (58.95) and for cost overrun forecasting model was (103.13). finally, this study can make (the contractors, clients, and consultants) avoid the risks of time and cost overrun for upcoming projects and get software as can predict the actual value for time and cost overrun percentages.

\section{REFERENCES}

[1] Assaf, S. A., \& Al-Hejji, S. (2006). Causes of delay in large construction projects. International journal of project management, 24(4), 349-357.

[2] Gunduz, M., Nielsen, Y., \& Ozdemir, M. (2015). Fuzzy assessment model to estimate the probability of delay in Turkish construction projects. Journal of Management in Engineering, 31(4), 04014055.

[3] Marzouk, M., \& Amin, A. (2013). Predicting construction materials prices using fuzzy logic and neural networks. Journal of construction engineering and management, 139(9), 1190-1198.

[4] Polat, G., \& Bingol, B. N. (2013). A comparison of fuzzy logic and multiple regression analysis models in determining contingency in international construction projects. Construction Innovation.

[5] Touran, A. (2003). Calculation of contingency in construction projects. IEEE Transactions on Engineering Management, 50(2), 135-140.

[6] Chang, S. S., \& Zadeh, L. A. (1996). On fuzzy mapping and control. In Fuzzy sets, fuzzy logic, and fuzzy systems: selected papers by Lotfi A Zadeh (pp. 180-184).

[7] Shibani, A. (2015, September). Time and Cost Overrun in Construction Projects in Egypt. 130150

[8] Abdul-Rahman, H., Wang, C., \& Yap, J. B. H. (2015). Impacts of design changes on construction project performance: Insights from a literature review. In 14th Management in Construction Researchers' Association (MiCRA 2015) Annual Conference and General Meeting.

[9] Olawale, Y. A., \& Sun, M. (2010). Cost and time control of construction projects: inhibiting factors and mitigating measures in practice. Construction management and economics, 28(5), 509-526.

[10] Dionisio, C. S. (2017). A Project Manager's Book of Forms: A Companion to the PMBOK Guide. John Wiley \& Sons. 
[11] Azhar, N., Farooqui, R. U., \& Ahmed, S. M. (2008, August). Cost overrun factors in construction industry of Pakistan. In First International Conference on Construction in Developing Countries (ICCIDC-I), Advancing and Integrating Construction Education, Research \& Practice (pp. 499-508).

[12] Memon, A. H., Abdul Rahman, I., \& Aziz, A. A. A. (2011). Time overrun in construction projects from the perspective of project management consultant (PMC). Journal of Surveying, Construction and Property, 2(1).

[13] Atout, M. M. (2016). Delays caused by project consultants and designers in construction projects. International Journal of Structural and Civil Engineering Research, 5(2), 102-107.

[14] Cooper, D. F., MacDonald, D. H., \& Chapman, C. B. (1985). Risk analysis of a construction cost estimate. International journal of project management, 3(3), 141-149.

[15] Khattab, M. M., \& Søyland, K. (1996). Limited-resource allocation in construction projects. Computers \& industrial engineering, 31(1-2), 229-232.

[16] Yu, D. (2010). Vendor Managed Inventory in the Swedish Construction Industry.

[17] Kadir, M. A., Lee, W. P., Jaafar, M. S., Sapuan, S. M., \& Ali, A. A. A. (2005). Factors affecting construction labor productivity for Malaysian residential projects. Structural survey.

[18] Hoek, E., \& Palmieri, A. (1998, September). Geotechnical risks on large civil engineering projects. In Proceedings of the 8th Congres IAEG (pp. 79-88).

[19] Mesa, H. A., Molenaar, K. R., \& Alarcón, L. F. (2016). Exploring performance of the integrated project delivery process on complex building projects. International Journal of Project Management, 34(7), 1089-1101.

[20] Ho, S. P., \& Liu, L. Y. (2004). Analytical model for analyzing construction claims and opportunistic bidding. Journal of construction engineering and management, 130(1), 94-104.

[21] Dixit, S., Pandey, A. K., Mandal, S. N., \& Bansal, S. (2017). A study of enabling factors affecting construction productivity: Indian scnerio. International Journal of Civil Engineering \& Technology, 8(6), 741-758.

[22] Mbachu, J. (2011). Sources of contractor's payment risks and cash flow problems in the New Zealand construction industry: Project team's perceptions of the risks and mitigation measures. Construction management and economics, 29(10), 1027-1041.

[23] Mohamed, M. A. B., Trigunarsyah, B., Teo, M., \& Kajewski, S. (2013). The impacts of FOREX fluctuations on construction business performance: an organisational capabilities perspective. In Proceedings of the Seventh International Conference on Construction in the 21st Century: Challenges in Innovation, Integration and Collaboration in Construction and Engineering (pp. 2-2).

[24] Salama, Kareem Mohammad, (2017), Using Artificial Neural Networks to Model the Cost Overruns in Real Estate Projects. IJRSI, 40-90.

[25] Jia, S. (2019). Toward a better fitness club: Evidence from exerciser online rating and review using latent Dirichlet allocation and support vector machine. International Journal of Market Research, 61(1), 64-76.

[26] Kannan, R., \& Vasanthi, V. (2019). Machine learning algorithms with ROC curve for predicting and diagnosing the heart disease. In Soft Computing and Medical Bioinformatics (pp. 63-72). Springer, Singapore. 
[27] Nawar, S. E. D. (2017). Owner time and cost contingency estimation for building construction projects in Egypt. MacDonald, D. H. (1983). PMI/ESA project time management function. Project Management Quarterly, 14(1), pp. (20-26).

[28] Parry, M. H. (1983). Cost management. Project Management Quarterly, 14(1), pp. (18-19).

[29] Singh, T., Di Troia, F., Corrado, V. A., Austin, T. H., \& Stamp, M. (2016). Support vector machines and malware detection. Journal of Computer Virology and Hacking Techniques, 12(4), 203-212

[30] Ameh, O. J., \& Osegbo, E. E. (2011). Study of relationship between time overrun and productivity on construction sites. International Journal of Construction Supply Chain Management, 1(1), 56-67.

[31] Subramani, T., Sruthi, P. S., \& Kavitha, M. (2014). Causes of cost overrun in construction. IOSR Journal of Engineering, 4(6), 1-7.

[32] Okpala, D. C., \& Aniekwu, A. N. (1988). Causes of high costs of construction in Nigeria. Journal of Construction Engineering and Management, 114(2), 233-244.

[33] Memon, A. H., \& Rahman, I. A. (2014). SEM-PLS analysis of inhibiting factors of cost performance for large construction projects in Malaysia: perspective of clients and consultants. The Scientific World Journal, 2014.

[34] Derakhshanalavijeh, R., \& Teixeira, J. M. C. (2017). Cost overrun in construction projects in developing countries, gas-oil industry of Iran as a case study. Journal of Civil Engineering and Management, 23(1), 125-136.

[35] Memon, A. H., Rahman, I. A., \& Azis, A. A. A. (2011). Preliminary study on causative factors leading to construction cost overrun. International Journal of Sustainable Construction Engineering and Technology, 2(1).

[36] Olawale, Y. A., \& Sun, M. (2010). Cost and time control of construction projects: inhibiting factors and mitigating measures in practice. Construction management and economics, 28(5), 509-526.

[37] Senouci, A., Ismail, A., \& Eldin, N. (2016). Time delay and cost overrun in Qatari public construction projects. Procedia engineering, 164, 368-375.

[38] Mukuka, M. J., Aigbavboa, C. O., \& Thwala, W. D. (2014, December). A theoretical review of the causes and effects of construction projects cost and schedule overruns. In International Conference on Emerging Trends in Computer and Image Processing (ICETCIP'2014) (pp. 1516).

[39] Akhund, M. A., Khoso, A. R., Memon, U., \& Khahro, S. H. (2017). Time overrun in construction projects of developing countries. Imperial Journal of Interdisciplinary Research, 3(5), 124-129.

[40] Sambasivan, M., \& Soon, Y. W. (2007). Causes and effects of delays in Malaysian construction industry. International Journal of project management, 25(5), 517-526.

[41] Marzouk, M. M., \& El-Rasas, T. I. (2014). Analyzing delay causes in Egyptian construction projects. Journal of advanced research, 5(1), 49-55.

[42] Chitkara, K. K. (1998). Construction project management. Tata McGraw-Hill Education. 